Article

\title{
Bioinspired ZnO-Based Solar Photocatalysts for the Efficient Decontamination of Persistent Organic Pollutants and Hexavalent Chromium in Wastewater
}

\author{
Albert Serrà ${ }^{1, * \mathbb{C}}$, Elvira Gómez ${ }^{2,3}$ (1) and Laetitia Philippe ${ }^{1}$ \\ 1 Empa, Swiss Federal Laboratories for Materials Science and Technology, Laboratory for Mechanics of \\ Materials and Nanostructures, Feuerwerkerstrasse 39, CH-3602 Thun, Switzerland; \\ laetitia.Philippe@empa.ch \\ 2 Grup d'Electrodeposició de Capes Primes i Nanoestructures (GE-CPN), Departament de Ciència de \\ Materials i Química Física, Universitat de Barcelona, Martí i Franquès, 1, E-08028 Barcelona, Catalonia, \\ Spain; e.gomez@ub.edu \\ 3 Institute of Nanoscience and Nanotechnology (IN2UB), Universitat de Barcelona, E-08028 Barcelona, \\ Catalonia, Spain \\ * Correspondence: albert.serraramos@empa.ch
}

Received: 24 October 2019; Accepted: 17 November 2019; Published: 20 November 2019

\begin{abstract}
Biomimetic/bioinspired engineering and sulfidation processes are effective strategies for improving the visible light-driven photocatalytic performance of $\mathrm{ZnO}$ photocatalysts. A facile electrodeposition process in high oxygen-flux conditions was used to synthesize well-defined fractal micro/nanoferns, consequently increasing the photocatalyst's light-trapping capability and the accessible active surface. Next, a simple sulfidation process was used to form a thin layer of ZnS, producing ZnO@ZnS core@shell micro/nanoferns, thereby tuning the optoelectronic properties and extending the photoresponse to the visible region. The $\mathrm{ZnO@ZnS} \mathrm{micro/nanoferns} \mathrm{exhibited} \mathrm{clear}$ superiority over other $\mathrm{ZnO}$ photocatalysts in the photooxidation of persistent organic pollutants (POPs) and the photoreduction of $\mathrm{Cr}(\mathrm{VI})$. Their excellent photocatalytic performance allowed the photodegradation under UV-filtered sunlight of nearly $97 \%$ of methylene blue after $60 \mathrm{~min}$; the mineralization of $>98 \%$ of a mixture of methylene blue, 4-nitrophenol, and rhodamine-B after $210 \mathrm{~min}$; and the removal of nearly $65 \%$ of $\mathrm{Cr}(\mathrm{VI})$ after $180 \mathrm{~min}$. In addition, the ZnO@ZnS micro/nanoferns demonstrated a good ability to decontaminate an inorganic-organic bipollutant system, with promising potential to leverage synergistic effects. Finally, these micro/nanoferns presented great recyclability and reusability for both photooxidation and photoremediation processes. These findings support that sulfidation and biomimetic engineering can be a superior route for designing efficient sunlight-driven $\mathrm{ZnO}$-photocatalysts for water decontamination.
\end{abstract}

Keywords: $\mathrm{ZnO}$; bioinspiration; electrodeposition; sunlight photocatalysis; persistent organic pollutants; hexavalent chromium removal

\section{Introduction}

$\mathrm{ZnO}$ photocatalysts are widely regarded as some of the most attractive semiconductor materials for photocatalytic engineering because of their low cost, high photosensitivity, sustainability properties, high redox potential, and high photocatalytic activity. However, the efficiency of $\mathrm{ZnO}$ photocatalysts is adversely affected by four key parameters: high photocorrosion activity, wide bandgap (3.3 eV), high electron mobility (200-300 $\left.\mathrm{cm}^{2} \mathrm{~V}^{-1} \mathrm{~s}^{-1}\right)$, and long electron lifetime (>10 s) [1-6].

Researchers have devoted considerable effort to developing smart strategies for the improvement of optoelectronic properties and photostability in $\mathrm{ZnO}$ photocatalysts through use of doping and 
surface modification. In addition, the development of hierarchical architectures promises to improve the adsorption of pollutants and the light-trapping capability of photocatalysts, as well as significantly enhancing their performance. Another approach for developing efficient photocatalysts is the integration of biomimetic and bioinspired thinking, such as in the design of novel sunlight-driven materials, devices, and structures. These take inspiration from the idea that sunlight has been the principal engine of most biological processes for millions of years. New and efficient photocatalysts developed through these methods show great promise, especially for water decontamination [1,7-10].

In the context of water decontamination, $\mathrm{ZnO}$ architectures have been considered for the photooxidation of a wide range of molecules, especially the mineralization of organic pollutants [11-14]. However, very little research has considered the use of $\mathrm{ZnO}$ for photoreduction reactions; where these reactions can be important for reducing heavy metals but have a lower impact on water decontamination [15-17]. For real-world applications, it is important to study both photooxidation and photoreduction processes, as (i) real wastewater is a complex, multi-pollutant-containing species that can be photo-oxidized or photo-reduced and (ii) the two processes/pollutant types can have synergistic photocatalytic effects.

In alkaline media, ZnO-based micro/nanoferns have demonstrated superior photocatalytic performance for the (photo)mineralization of single-pollutant solutions of methylene blue (MB), 4-nitrophenol (4-NP), and rhodamine B (Rh-B). This effect is largely a result of ZnO-based micro/nanoferns having a large surface area, abundant active sites for pollutant reaction, and a fractal architecture that facilitates an outstanding ability to trap incident light at any angle. However, the photocatalytic performance of $\mathrm{ZnO}$-based micro/nanoferns in complex environments, including saline and multi-pollutant solutions, has not yet been explored [1].

In the study presented here, electrodeposited biomimetic ZnO-based micro/nanoferns were fully investigated for use as simple, inexpensive, effective photocatalysts in (i) the photooxidation of a mixture of three persistent pollutants (POPs) - MB, 4-NP, and Rh-B - and (ii) the photoreduction of $\mathrm{Cr}(\mathrm{VI})$ to $\mathrm{Cr}(\mathrm{III})$ under irradiation with natural and simulated UV-filtered sunlight. Through these processes, we examined the effects of bioinspired architecture and surface modification on pollutant adsorption, photocatalytic decontamination, and photocorrosion resistance. In addition, approaching to a more realistic system, an $\mathrm{MB} / \mathrm{Cr}(\mathrm{VI})$ system was used to evaluate the possible synergic effects of organic-inorganic pollutants on photooxidation and photoreduction. Solutions were prepared in a saline medium that mimicked natural environments. The excellent catalytic performance in the photooxidation of POPs and the photoreduction of $\mathrm{Cr}(\mathrm{VI})$ supports the potential of surface modification and biomimetics to supply efficient architectures using a simple, inexpensive, and scalable synthetic approach based on electrodeposition and sulfidation processes.

\section{Results and Discussion}

\subsection{Electrosynthesis and Characterization}

Electrodeposition has proven to be an excellent technique for the deposition of vertically-aligned $\mathrm{ZnO}$ nanowires with well-defined dimensions. The nanowire attributes are dictated by controlling $\mathrm{Zn}$ (II) concentration, bath composition, deposition time, charge density, and substrate, among other parameters [18,19]. However, the single most important aspect is the reduction of an oxygen precursor (i.e., nitrate ions, dissolved molecular oxygen, or hydrogen peroxide) at the interface electrode, resulting in the electro-generation of hydroxyl ions and, consequently, the electro-precipitation of $\mathrm{ZnO}$. This reduction reaction controls the nanowire growth rate and determines its morphology and crystallinity $[18,19]$. Recent studies have shown that by using molecular oxygen under turbulent conditions, arrays of well-defined micro/nanoferns, with fractal architectures that provide significantly greater surface area, can be easily electrodeposited [1,20].

As shown in Figure 1, strong stirring conditions (400 rpm of magnetic stirring and $12 \mathrm{~L} \mathrm{~min}^{-1}$ of oxygen bubbling) do not affect the preferred growth of $\mathrm{ZnO}$, which has lower energy than does 
growth along other planes. However, stirring conditions do drastically affect architecture. By controlling the oxygen flux, the nanowire ramification can easily be controlled (Table 1, Figure 1a-c). Therefore, oxygen flux is an important factor in the electrodeposition of $\mathrm{ZnO}$; specifically, the turbulent regime promotes the formation of new growth nuclei on previously-deposited $\mathrm{ZnO}$, which introduces the creation of multiple ramifications.
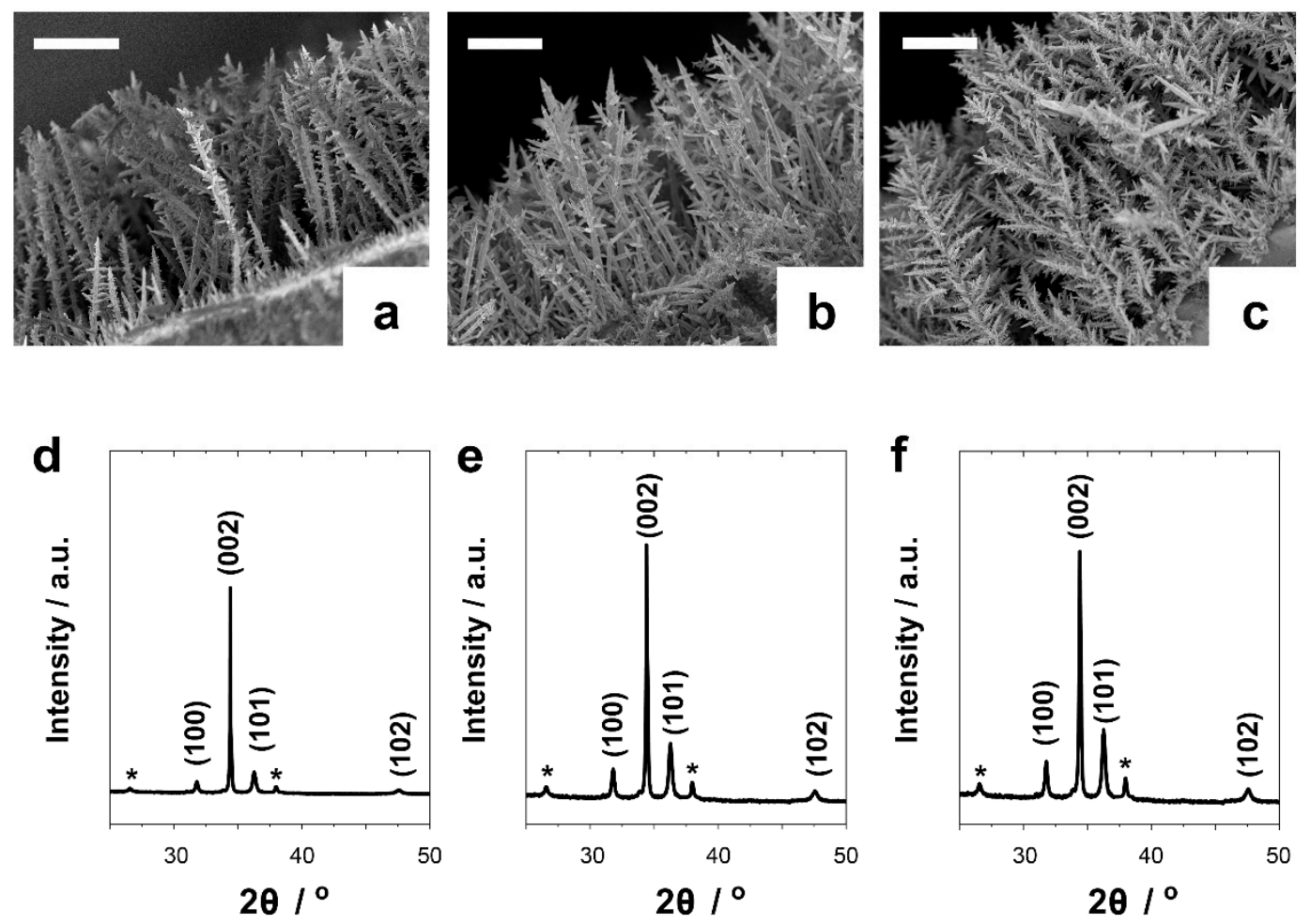

Figure 1. (a-c) FE-SEM micrographs and (d-f) XRD patterns of $\mathrm{ZnO}$ microstructures electrodeposited on a fluorine-doped tin oxide film on a glass substrate under different oxygen flux bubbling conditions: $(\mathbf{a}, \mathbf{d}) 1 \mathrm{~L} \mathrm{~min}^{-1},(\mathbf{b}, \mathbf{e}) 3 \mathrm{~L} \mathrm{~min}^{-1}$, and (c,f) $12 \mathrm{~L} \mathrm{~min}^{-1}$. Scale bar: $20 \mu \mathrm{m}$. Diffraction peaks that correspond to fluorine-doped tin oxide substrate structures are indicated with $\mathrm{a}^{*}$.

Table 1. Oxygen flux, magnetic stirring and potential used in the electrodeposition process, and morphology, structure, and BET surface area of electrodeposited micro/nanoferns.

\begin{tabular}{cccccc}
\hline $\begin{array}{c}\text { Oxygen } \\
\text { Flux/L } \mathbf{~ m i n}^{\mathbf{1}}\end{array}$ & $\begin{array}{c}\text { Magnetic } \\
\text { Stirring/rpm }\end{array}$ & $\begin{array}{c}\text { Potential/V vs. } \\
\mathbf{A g} / \mathbf{A g C l} / \mathbf{K C l} \mathbf{( 3 ~ M )}\end{array}$ & Morphology & $\begin{array}{c}\text { Structure } \\
\text { (Preferred Growth) }\end{array}$ & $\begin{array}{c}\text { BET Surface } \\
\mathbf{A r e a}^{\mathbf{2}} \mathbf{m}^{\mathbf{- 1}}\end{array}$ \\
\hline 1 & 400 & -1 & Low ramification & ZnO wurtzite (002) & $38.2 \pm 1.8$ \\
3 & 400 & -1 & Moderate & ZnO wurtzite (002) & $42.1 \pm 1.2$ \\
12 & 400 & -1 & High ramification & ZnO wurtzite (002) & $67.4 \pm 1.2$ \\
\hline
\end{tabular}

All electrodeposited architectures had similar diffraction patterns with an intense peak at $2 \theta=34.42^{\circ}$, corresponding to the preferential orientation along the (002) axis. Additionally, less intense diffraction peaks were observed at $2 \theta=31.79^{\circ}, 36.25^{\circ}$, and $47.53^{\circ}$; and these perfectly matched with the (100), (101), and (102) planes of the hexagonal wurtzite phase (JCPDS card no. 36-1451). Additional diffraction peaks located at $2 \theta=26.61^{\circ}$ and $37.95^{\circ}$ were attributed to the fluorine-doped tin oxide substrate.

Note that the increased ramification of the central wire significantly increased the effective surface area (Table 1), which could be beneficial for heterogeneous photocatalysis. For this reason, we selected high ramification micro/nanoferns as the subject of this work.

Although the micro/nanofern architecture of $\mathrm{ZnO}$ is very efficient in the absorption of light and pollutants, its low catalytic activity and low photocorrosion resistance under sunlight irradiation 
inhibit its use as a photocatalyst. Both photocatalytic performance and photocorrosion resistance under sunlight irradiation are conventionally improved by various surface modification or doping strategies [1,21-24]. Photocatalytic reactions are largely superficial processes, and consequently, the adsorption and desorption kinetics and affinity are the determinants of photocatalytic performance. The formation of a thin $\mathrm{ZnS}$ surface layer improves the adsorption affinity of $\mathrm{ZnO}$ nano/microferns and possibly has positive effects on the photooxidation or photoreduction processes.

In this study, we investigated the formation of $\mathrm{ZnO@ZnS} \mathrm{core@shell} \mathrm{micro/nanoferns} \mathrm{using} \mathrm{a}$ simple and inexpensive sulfidation process. The formation of $\mathrm{ZnO@ZnS} \mathrm{core@shell} \mathrm{micro/nanoferns}$ was confirmed by XRD (Figure 2 and Figure S1), with two extra peaks appearing for all microstructures at $2 \theta=28.55^{\circ}$ (111) and $33.87^{\circ}(200)$. These peaks match perfectly with the cubic ZnS blended structure (JCPDS card no. 65-1691). Notably, the ZnS thickness varied depending on the area of the micro/nanofern under study because of the different stabilities and reactivities of different micro- and nano-metric ramifications. As shown in Figure S2, the surface roughness increased with increased sulfidation time, which could be beneficial for photocatalysis. At low sulfidation times (up to four hours), the increased surface roughness did not affect micro/nanofern architecture, and the BET surface area slightly increased from $67.4 \mathrm{~m}^{2} \mathrm{~g}^{-1}$ ( $\mathrm{ZnO}$ micro/nanoferns) to $70.6 \mathrm{~m}^{2} \mathrm{~g}^{-1}$ (ZnO@ZnS(4 h) micro/nanoferns). However, at high sulfidation times (more than four hours), the micro/nanofern architecture was negatively affected, where microstructures became more compact, and the increase in roughness did not compensate for the loss of effective area. Consequently, the BET surface area significantly decreased to $53.9 \mathrm{~m}^{2} \mathrm{~g}^{-1}$ (ZnO@ZnS(8 h) micro/nanoferns) and $30.3 \mathrm{~m}^{2} \mathrm{~g}^{-1}$ (ZnO@ZnS(12 h) micro/nanoferns). Accordingly, ZnO@ZnS(4 h) micro/nanoferns were selected for the photocatalytic experiments.

a
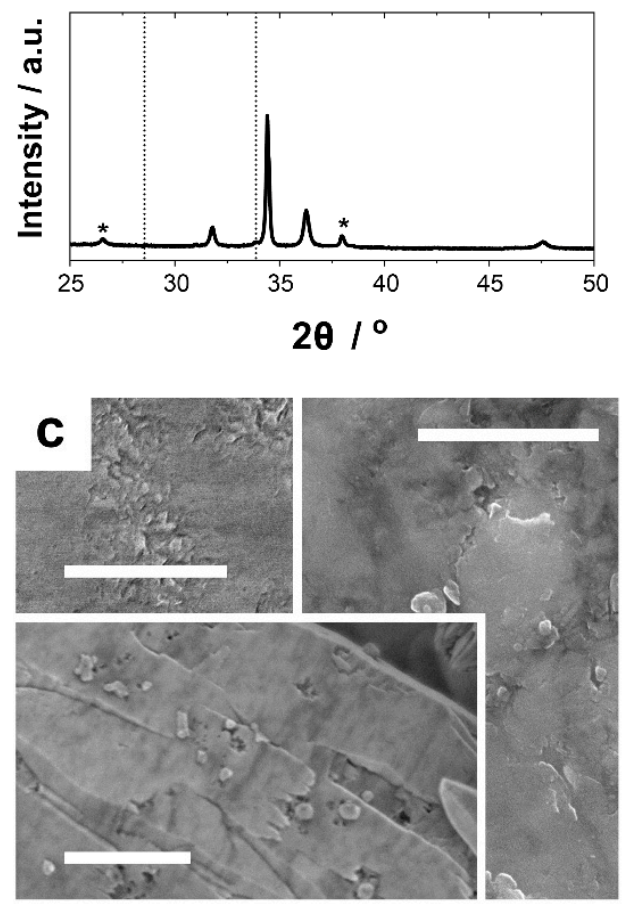

b


Figure 2. XRD patterns of (a) $\mathrm{ZnO}$ and (b) ZnO@ZnS(4 h) micro/nanoferns. Diffraction peaks corresponding to the $\mathrm{ZnS}$ blende and fluorine-doped tin oxide substrate structures are indicated with a dashed line and *, respectively. FE-SEM micrographs of (c) ZnO and (d) ZnO@ZnS(4 h) micro/nanoferns. Scale bar: $200 \mathrm{~nm}$.

It is well-known that for solar light-harvesting applications, the $\mathrm{ZnO}$ and $\mathrm{ZnS}$ bandgap can drastically be reduced by forming layered $\mathrm{ZnO}$ heterostructures. Similarly, the use of heterojunction structures such as $\mathrm{ZnO} / \mathrm{ZnS}$ or $\mathrm{ZnO} / \mathrm{Bi}_{2} \mathrm{~S}_{3}$ is a promising strategy for improving the optoelectronic 
properties and photocorrosion resistance of $\mathrm{ZnO}$ photocatalysts for water decontamination [1,20,24]. As shown in Figure 3, the use of short sulfidation times (4h) not only allowed the creation of a ZnO@ZnS core@shell structure without affecting the micro/nano-fern-shaped architecture (i.e., improved light trapping and pollutant adsorption), but it also allowed reduction of the bandgap of $\mathrm{ZnO}$ micro/nanoferns $\left(\mathrm{E}_{\mathrm{g}}=3.26 \mathrm{eV}\right)$ to $2.88 \mathrm{eV}(\mathrm{ZnO} @ \mathrm{ZnS}(4 \mathrm{~h})$ micro/nanoferns), thereby extending the photoresponse from UV to the visible domain. Moreover, compared to nude $\mathrm{ZnO}$, the formation of a $\mathrm{ZnO} / \mathrm{ZnS}$ heterostructure is known to improve the separation efficiency of photogenerated electrons and holes (i.e., reducing the recombination process). Consequently, $\mathrm{ZnO@ZnS(4h)} \mathrm{micro/nanoferns} \mathrm{were} \mathrm{expected} \mathrm{to}$ exhibit enhanced photooxidation and photoreduction properties.

a

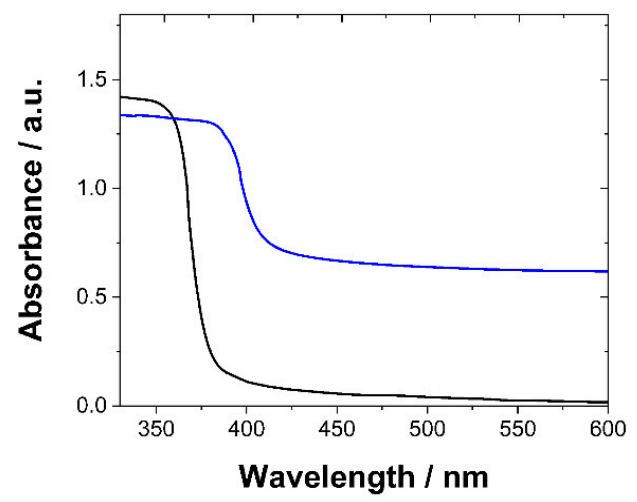

b

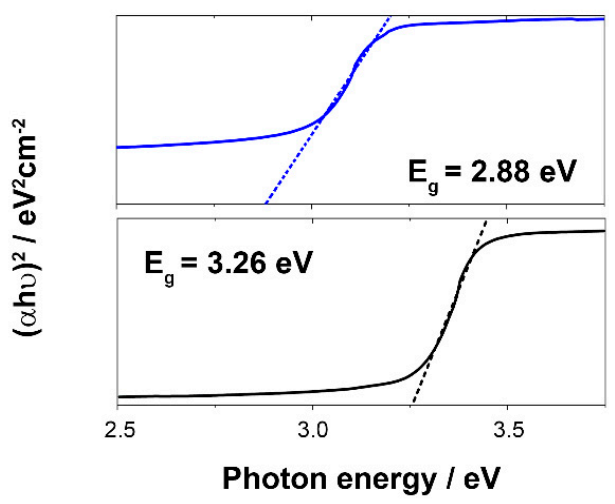

- ZnO@Zns

Figure 3. (a) UV-vis DRS absorption spectra and (b) Tauc plots from the UV-vis analysis of $\mathrm{ZnO}$ and $\mathrm{ZnO@ZnS(4h)} \mathrm{micro/nanoferns.}$

\subsection{Adsorption Experiments}

We performed adsorption experiments under dark conditions to discriminate the effect of adsorption on the photo-removal of both persistent organic pollutants and $\mathrm{Cr}(\mathrm{VI})$ ions under subsequent sunlight irradiation. Adsorption behavior is highly dependent on the surface charges of the adsorbent (photocatalyst) and the adsorbate (pollutant); thus, the adsorption capability depends on the solution $\mathrm{pH}$.

Adsorption experiments were performed in an alkaline saline medium $(\mathrm{pH}=9.5)$, and both $\mathrm{MB}$ and $\mathrm{Cr}(\mathrm{VI})$ pollutants were effectively adsorbed by ZnO-based micro/nanoferns (Figure 3). For all tested photocatalysts, adsorption increased sharply during the initial twenty minutes due to the presence of free active sites on the adsorbent, then it reached a plateau at forty minutes. The same trend was observed for both types of pollutants. Therefore, the duration of ninety minutes was selected for use in experiments to ensure the achievement of adsorption-desorption equilibrium before beginning sunlight irradiation (i.e., the photooxidation and photoreduction processes). The maximum absorption capacity was higher for $\mathrm{Cr}(\mathrm{VI})$ than for $\mathrm{MB}$, possibly due to the chemical properties of each pollutant, such as radius and charge density. Importantly, for a similar BET surface area, adsorption affinities were significantly higher for $\mathrm{ZnO} @ \mathrm{ZnS}(4 \mathrm{~h})$ core@shell micro/nanoferns than $\mathrm{ZnO}$ micro/nanoferns.

\subsection{Photooxidation of POPs}

Developing strategies for the efficient removal of POPs is extremely important for three reasons. First, traditional water decontamination technologies are inefficient at removing POPs, resulting in their considerable persistence. Second, POPs can travel long distances due to their easy evaporation and easy adsorption on solids; consequently, they have been observed to accumulate in areas far from any source, including Antarctica. Third, POPs achieve high bioaccumulation in microorganisms, which adversely affects biota and human health around the world [11-13]. 
This study evaluated the efficiency of ZnO-based micro/nanoferns at decontaminating through photooxidative mineralization of a single-pollutant ( $5 \mathrm{ppm}$ of MB, $5 \mathrm{ppm}$ of 4-NP, $5 \mathrm{ppm}$ of Rh-B or $20 \mathrm{ppm}$ of $\mathrm{Cr}(\mathrm{VI}))$ and a multi-pollutant solution ( $5 \mathrm{ppm}$ of $\mathrm{MB}+5 \mathrm{ppm}$ of $4-\mathrm{NP}+5 \mathrm{ppm}$ of Rh-B) in a high saline and alkaline environment under artificial and natural UV-filtered sunlight irradiation. To rule out potential photolytic degradation without catalysts (i.e., photolysis), we also subjected single-pollutant solutions ( $5 \mathrm{ppm}$ of $\mathrm{MB}, 5 \mathrm{ppm}$ of 4-NP, and $5 \mathrm{ppm}$ of Rh-B) to light alone; conditions at which these reactions showed a negligible effect compared to the photocatalysts (Figure S3).

For the photooxidation of $\mathrm{MB}$, photocatalytic activities were determined by measuring the decrease of its UV-vis absorption spectrum at successive time points during irradiation (Figure $4 a, b)$. According to the Langmuir-Hinshelwood model, when the concentration of reactant is low, a pseudo-first-order reaction can be used to determine the degradation kinetics $[25,26]$. The observed linear relationship for MB (Figure S4) confirmed pseudo-first-order kinetics, which allowed the mass-normalized degradation rate constant to be calculated. ZnO@ZnS micro/nanoferns showed the best catalytic performance, with a degradation rate constant of $9.74 \mathrm{~min}^{-1} \mathrm{~g}^{-1}$ in artificial sunlight, approximately 4.4 times greater than that of $\mathrm{ZnO}$ micro/nanoferns. For the photooxidation of 4-NP and Rh-B, photocatalytic activities were determined by measuring the reduction in the maximum absorption peak intensity of 4-NP $(400 \mathrm{~nm})$ and Rh-B (554 nm), respectively, under artificial and natural irradiation over $60 \mathrm{~min}$ (Figure S5). As expected, ZnO@ZnS micro/nanoferns exhibited the best photocatalytic performance under artificial sunlight irradiation, with a degradation rate constant (assuming a pseudo-first-order reaction) of $8.95 \mathrm{~min}^{-1} \mathrm{~g}^{-1}$ and $8.69 \mathrm{~min}^{-1} \mathrm{~g}^{-1}$ for 4-NP and Rh-B, respectively. The same tendency occurred when natural sunlight was used as the light source. Importantly, the catalytic performance of ZnO@ZnS micro/nanoferns in the photoremediation of $\mathrm{MB}, 4-\mathrm{NP}$, or Rh-B was comparable to or better than that of the most competitive state-of-the-art $\mathrm{ZnO}$ photocatalysts [27-33].

a

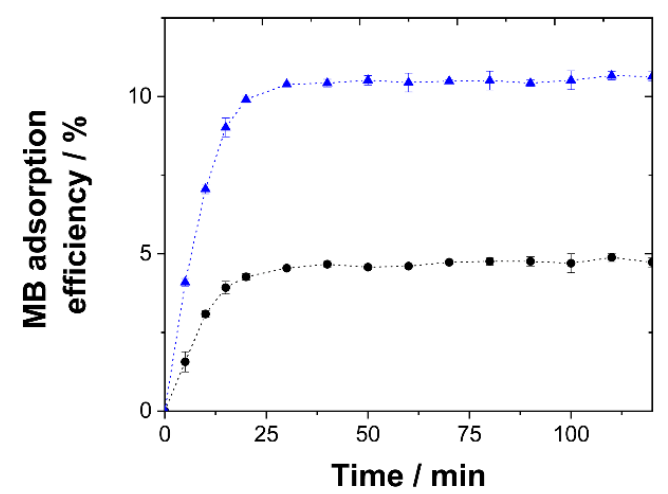

b

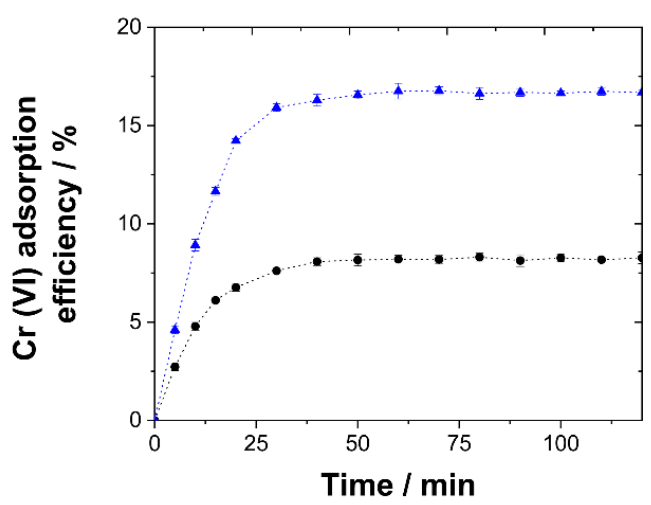

Figure 4. Adsorption efficiency of (a) MB and (b) $\mathrm{Cr}(\mathrm{VI})$ for $(\bullet) \mathrm{ZnO}$ and ( $\mathbf{\wedge}) \mathrm{ZnO} @ \mathrm{ZnS}(4 \mathrm{~h})$ micro/nanoferns under dark conditions (adsorbent dosage $=0.4 \mathrm{mg} \mathrm{mL}^{-1}, \mathrm{pH}=9.5$, and $\mathrm{T}=25.0 \pm 0.1^{\circ} \mathrm{C}$ ).

It is well-known that the photooxidation efficiency of POPs drastically depends on the $\mathrm{pH}$ value, mainly due to the pollutant adsorption capacity being determined by electrostatic attraction or repulsion, which is influenced by surface charge and the ionic (i.e., anionic or cationic) form of the POP. Media pH also has a non-trivial effect on photomineralization as it affects (i) the electrostatic interactions between photocatalyst surface, solvent, pollutant molecules, and charged radicals formed during the irradiation process (mainly on the photocatalyst surface); and (ii) the chemical and photochemical stability of the photocatalyst, which can drastically affect the photocatalyst's lifetime. Consequently, the role of $\mathrm{pH}$ in water decontamination must be considered and explored to propose effective photocatalysts for such applications. Here, the effect of $\mathrm{pH}$ on $\mathrm{MB}$ photodegradation efficiency was studied at $\mathrm{pH}$ 5.5, 7.5, and 9.5. As shown in Figure $5 c$, the photodegradation efficiency of $\mathrm{MB}$ was significantly higher in alkaline conditions, which could be attributed to the greater interaction between the photocatalyst and $\mathrm{MB}$ (note that MB is a cationic compound) and to the high hydroxylation of the photocatalyst surface as a 
consequence of the large amount of hydroxyl ions, which translated to the more efficient formation of hydroxyl radicals [34-36]. More importantly, recycling experiments using ZnO-based micro/nanoferns at different $\mathrm{pH}$ demonstrated that in more acidic environments, the recyclability was significantly decreased, indicating that $\mathrm{ZnO}$ dissolution and photocorrosion increased. However, $\mathrm{ZnO} @ \mathrm{ZnS}$ micro/nanoferns maintained excellent photocatalytic performance when recycled/reused (Figure 5c), especially in alkaline conditions, due to having minimal photocorrosive activity.

a

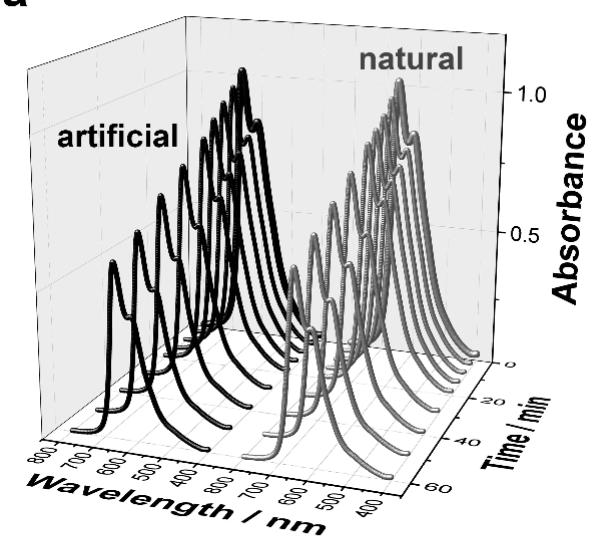

b

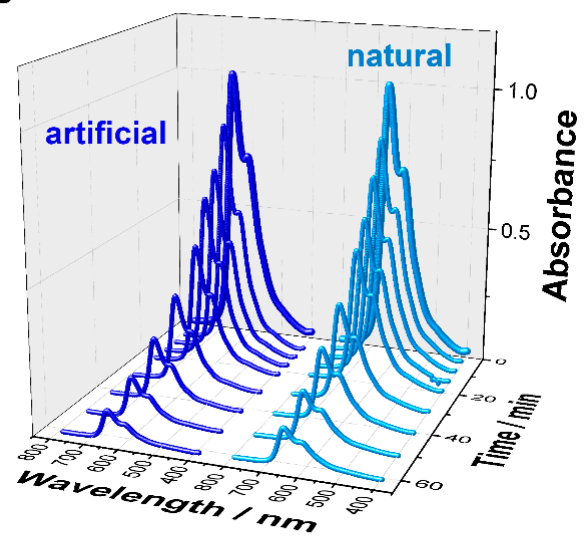

C

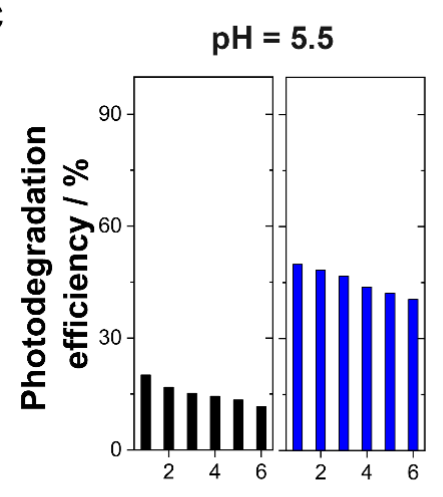

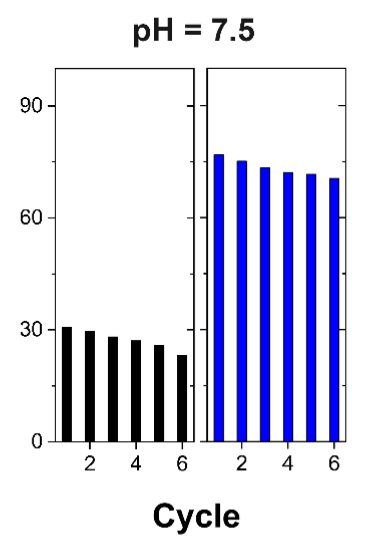

- $\mathrm{ZnO}$

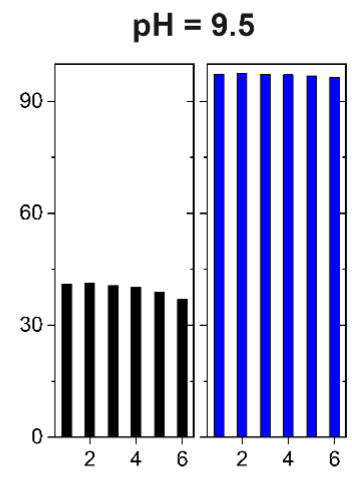

Figure 5. Time-dependent UV-vis spectra of MB (5 ppm) photocatalytically degraded under artificial and natural UV-filtered $\left(\lambda>400 \mathrm{~nm}\right.$ ) sunlight in the presence of $0.4 \mathrm{mg} \mathrm{mL}^{-1}$ of (a) $\mathrm{ZnO}$ micro/nanoferns and (b) ZnO@ZnS micro/nanoferns. (c) Effectiveness of recycled ZnO-based micro/nanoferns in MB photodegradation of MB under artificial UV-filtered $(\lambda>400 \mathrm{~nm})$ sunlight at different $\mathrm{pH}$ levels $(5.5,7.5$, and 9.5) (Irradiation time $=60 \mathrm{~min}$, photocatalyst dosage $=0.4 \mathrm{mg} \mathrm{mL}^{-1}$, and $\mathrm{T}=25.0 \pm 0.1{ }^{\circ} \mathrm{C}$ ).

It is well-known that reactive oxygen species (ROS) generated by the photocatalyst can efficiently oxidize $\mathrm{MB}$ into $\mathrm{CO}_{2}$, although this process involves numerous steps, and thus, is slower than the simple photodegradation of MB. Consequently, the TOC reduction efficiencies for MB showed a similar trend as the UV-vis measurements (Table 2), although relatively less pronounced. 
Table 2. Photocatalytic degradation efficiency of MB (5 ppm) polluted saline solutions under artificial sunlight $(\lambda>400 \mathrm{~nm})$ and natural sunlight $(\lambda>400 \mathrm{~nm})$ using $\left(0.4 \mathrm{mg} \mathrm{mL}^{-1}\right) \mathrm{ZnO}$ and $\mathrm{ZnO@ZnS} \mathrm{core@shell} \mathrm{bioinspired} \mathrm{fern-shape} \mathrm{microleaves.}$

\begin{tabular}{|c|c|c|c|c|c|c|}
\hline \multirow{2}{*}{ Photocatalyst } & \multicolumn{3}{|c|}{ Artificial UV-Filtered Sunlight Irradiation $(60 \mathrm{~min} \lambda>400 \mathrm{~nm})$} & \multicolumn{3}{|c|}{ Natural UV-Filtered Sunlight Irradiation $(60 \min \lambda>400 \mathrm{~nm})$} \\
\hline & $\begin{array}{l}\text { Degradation } \\
\text { Efficiency } / \%\end{array}$ & $\begin{array}{l}\text { Mass Normalized } \\
\text { Kinetic/min } \text { min }^{-1} \mathrm{~g}^{-1}\end{array}$ & $\begin{array}{l}\text { Mineralization } \\
\text { Efficiency } / \%\end{array}$ & $\begin{array}{l}\text { Degradation } \\
\text { Efficiency/\% }\end{array}$ & $\begin{array}{l}\text { Mass Normalized } \\
\text { Kinetic/min } \text { min }^{-1}\end{array}$ & $\begin{array}{l}\text { Mineralization } \\
\text { Efficiency/\% }\end{array}$ \\
\hline $\mathrm{ZnO}$ micro/nanoferns & $41 \pm 2$ & 2.21 & $21.5 \pm 1.1$ & $36 \pm 2$ & 1.83 & $18.2 \pm 0.6$ \\
\hline $\begin{array}{c}\text { ZnO@ZnS } \\
\text { micro/nanoferns }\end{array}$ & $97 \pm 1$ & 9.74 & $73.1 \pm 1.6$ & $88 \pm 2$ & 8.65 & $64.9 \pm 0.8$ \\
\hline
\end{tabular}


We also tested the photooxidation capacity of ZnO-based micro/nanoferns by quantifying the reduction of a complex multipollutant solution in the TOC content after $210 \mathrm{~min}$ of irradiation using artificial and natural UV-filtered sunlight. The kinetics of the photodegradation of each pollutant was not determined because only the total photooxidation of the mixtures was analyzed. As shown in Figure 6, ZnO@ZnS micro/nanoferns were by far the most efficient (>80\%) microstructures for water remediation under solar light irradiation.



Figure 6. Mineralization efficiency of $\mathrm{ZnO}$-based micro/nanoferns on a multi-pollutant solution under artificial and natural UV-filtered $(\lambda>400 \mathrm{~nm}$ ) sunlight irradiation (Irradiation time $=210 \mathrm{~min}$, photocatalyst dosage $=0.4 \mathrm{mg} \mathrm{mL}^{-1}$, and $\mathrm{T}=25.0 \pm 0.1^{\circ} \mathrm{C}$ ).

ZnO@ZnS biomimetic micro/nanoferns have excellent photooxidation performance for three typical POPs. However, these results may not generalize to other complex solutions, as the mineralization rate of each pollutant can be dramatically affected by the surface affinities of other solution constituents on account of the competition between pollutants and photogenerated intermediates for a limited number of active sites and the interactions between pollutants and intermediates.

\subsection{Photoreduction of $\mathrm{Cr}(\mathrm{VI})$}

The rapid industrialization of developing countries, where environmental policies are less strict, has prompted the accumulation of heavy metal ions in water. One such is hexavalent chromium, which is widely used in several industrial applications, including industrial electroplating and metal processing, and has been listed as a priority contaminant by the U.S. Environmental Protection Agency because of its high mutagenic and carcinogenic activity [14-17]. Accordingly, methods for the removal of hexavalent chromium are urgently needed. Among current technologies for pollutant removal, the photocatalytic reduction is cost-efficient and easy to employ, attributes that are fundamental for application in developing countries.

Therefore, the performance of $\mathrm{ZnO}$-based micro/nanoferns in the photoreduction of $\mathrm{Cr}(\mathrm{VI})$ was further investigated. Blank experiments (i.e., without photocatalysts) demonstrated that a $\mathrm{Cr}(\mathrm{VI})$ solution prepared in alkaline and saline media A was highly stable under both artificial and natural UV-filtered sunlight irradiation (Figure S6). In contrast, after $180 \mathrm{~min}$ under artificial UV-filtered sunlight in the presence of $\mathrm{ZnO}$ and $\mathrm{ZnO} @ \mathrm{ZnS}$ micro/nanoferns, $\mathrm{Cr}(\mathrm{VI})$ removal efficiency reached almost 36\% and $60 \%$, respectively (Figure $7 \mathrm{a}, \mathrm{b}$ ). The same trend was observed when using natural UV-filtered sunlight. Note that the removal percentage included both the adsorption and photoreduction of $\mathrm{Cr}(\mathrm{VI})$. Nonetheless, the results indicated that $\mathrm{Cr}(\mathrm{VI})$ removal was predominantly a consequence of the photoreduction process. Furthermore, the reduction of $\mathrm{Cr}(\mathrm{VI})$ to $\mathrm{Cr}(\mathrm{III})$ could be visually observed, as the solution color progressed from bright-yellow to greenish during the irradiation period. 
a

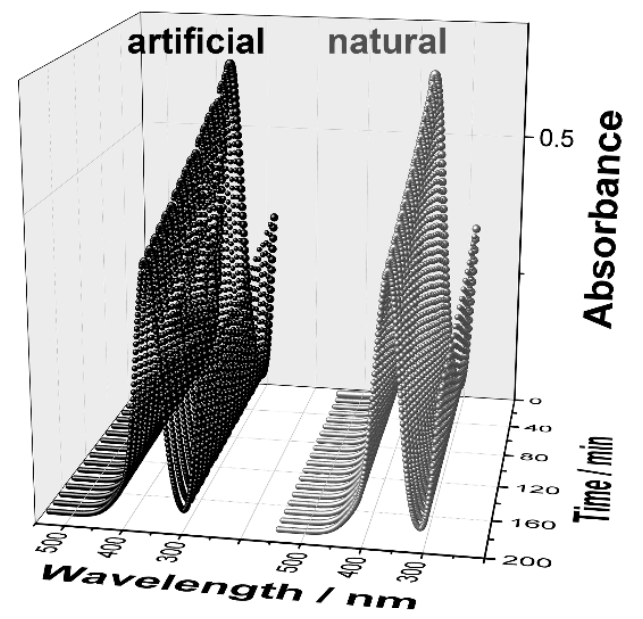

b

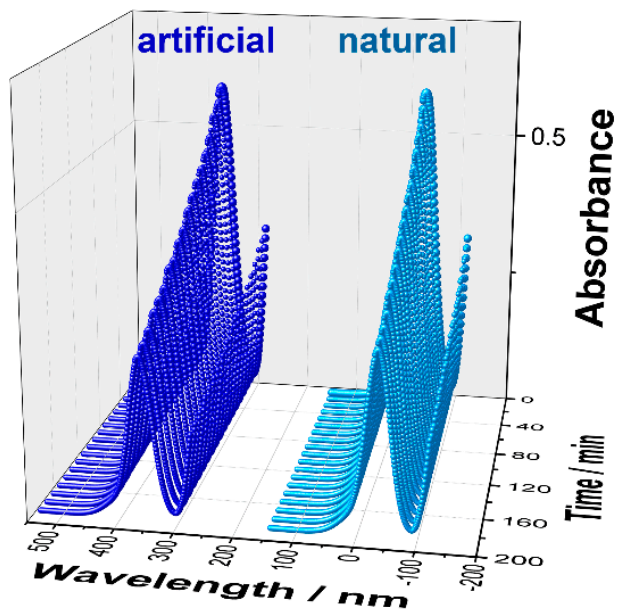



Figure 7. Time-dependent UV-vis spectra of the photocatalytic reduction of $\mathrm{Cr}(\mathrm{VI})$ (20 ppm) under artificial and natural UV-filtered $\left(\lambda>400 \mathrm{~nm}\right.$ ) sunlight by $0.4 \mathrm{mg} \mathrm{mL}^{-1}$ of the (a) $\mathrm{ZnO}$ and (b) ZnO@ZnS biomimetic fern-like microleaves. (c) Effectiveness of recycled ZnO-based micro/nanoferns in photoreduction of $\mathrm{Cr}(\mathrm{VI})$ under artificial UV-filtered $(\lambda>400 \mathrm{~nm}$ ) sunlight (Irradiation time $=180 \mathrm{~min}$, photocatalyst dosage $=0.4 \mathrm{mg} \mathrm{mL}^{-1}$, and $\mathrm{T}=25.0 \pm 0.1^{\circ} \mathrm{C}$ ).

To determine the photocatalytic activity for the removal of $\mathrm{Cr}(\mathrm{VI})$, we selected a pseudo-first-order kinetic model (Figure S7). When artificial UV-filtered sunlight was used, the photoreduction constant of $\mathrm{ZnO} @ \mathrm{ZnS}\left(4.23 \times 10^{-3} \mathrm{~min}^{-1}\right)$ micro/nanoferns was 2.0 times that of $\mathrm{ZnO}\left(2.08 \times 10^{-3} \mathrm{~min}^{-1}\right)$ micro/nanoferns. This photocatalytic performance was comparable to previously published reports on $\mathrm{Cr}(\mathrm{VI})$ removal by ZnO-based photocatalysts [14-17,33,37]. Additionally, as shown in Figure 7c, ZnO@ZnS micro/nanoferns maintained their excellent photocatalytic performance over multiple cycles of reuse owing to minimal photocorrosive activity.

\subsection{Synergetic Effects of Organic-Inorganic Pollutants on Photooxidation and Photoreduction Processes}

Photooxidation and photoreduction processes are intrinsically interrelated [38-40]. Oxidants, such as oxygen or heavy metals, are required for the photooxidation of organic compounds, while reductants, such as organic compounds or water, are required for the photoreduction of heavy metals. Therefore, synergetic effects between the two processes are expected, depending on the nature of the pollutant solution. Furthermore, although industrial wastewater contains a combination of various pollutants such as POPs, $\mathrm{Cr}(\mathrm{VI})$, and other heavy metals [1-3,41,42], only a few studies have addressed the simultaneous removal of both organic and inorganic pollutants in complex environments. 
It is known that organic donors, such as hole scavengers (e.g., triethanolamine), can accelerate $\mathrm{Cr}(\mathrm{VI})$ photoreduction while hindering its photodegradation [38-40]. Therefore, constituents in organic-inorganic multi-pollutant systems can induce synergetic positive or negative effects on global photocatalytic performance depending on their surface affinity, nature, and mechanism of photodegradation. Note that pollutant adsorption can also modify the photocatalyst surface, which can positively or negatively affect its activity. Therefore, on account of all these factors, competitive photocatalysts must be at least tested in organic-inorganic multi-pollutant systems before being proposed as efficient photocatalysts for water decontamination.

A large portion of photogenerated electron-hole pairs recombine during the photocatalytic process, dissipating the harvested energy in the form of heat or light emission (Equation (1)) [39-43] and hindering photodegradation activity.

$$
e^{-}+h^{+} \rightarrow \text { heat (or light emission) }
$$

Photogenerated holes and hydroxyl radicals govern MB photodegradation when ZnO@ZnS photocatalysts are used. Consequently, inhibition of the recombination process can significantly increase MB photodegradation. Therefore, synergetic effects between organic-inorganic pollutants and organic-photocatalyst or inorganic-photocatalyst interactions can effectively promote the photocatalytic decontamination of wastewater.

As shown in Figure 8, MB photodegradation is significantly promoted in the presence of $\mathrm{Cr}(\mathrm{VI})$ due to inhibition of the recombination process; specifically, the kinetic constant of MB degradation by $\mathrm{ZnO@ZnS} \mathrm{increased} \mathrm{from} 9.74 \mathrm{~min}^{-1} \mathrm{~g}^{-1}$ to $14.0 \mathrm{~min}^{-1} \mathrm{~g}^{-1}$. The improvement was less significant for nude $\mathrm{ZnO}$ micro/nanoferns. Moreover, the photoreduction of $\mathrm{Cr}(\mathrm{VI})$ was slightly improved in the presence of MB. This effect could be easily explained as a result of $\mathrm{Cr}(\mathrm{VI})$ ions capturing photogenerated electrons from the photoreduction process, which also inhibited recombination.

a



- $\mathrm{ZnO}$ b

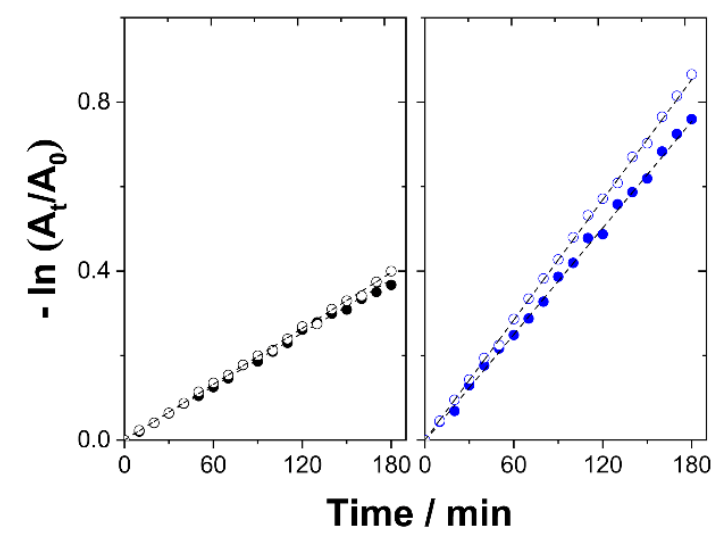

- ZnO@ZnS

Figure 8. (a) Photodegradation efficiency of MB (5 ppm) in the presence $(\bullet)$ and absence $(\bigcirc)$ of $\operatorname{Cr}(\mathrm{VI})$ ions (20 ppm) under artificial UV-filtered sunlight. (b) Photoreduction efficiency of $\mathrm{Cr}(\mathrm{VI})$ (20 ppm) in the presence $(\bullet)$ and absence $(\bigcirc)$ of MB (5 ppm) under artificial UV-filtered sunlight.

ZnO@ZnS micro/nanoferns are promising candidates for the photocatalytic decontamination of water due to their excellent photooxidation and photoreduction activities, as well as improved photocorrosion resistance. The combination of two synergetic effects can explain the promising properties of these sulfidated structures for photocatalytic applications: first, the chemical composition that determines their intrinsic properties (i.e., physical, chemical, and ecological); and, second, the shape 
and architecture that strongly determine not only the affinity and surface reactivity of the photocatalysts but also their light-trapping ability.

\section{Materials and Methods}

\subsection{Electrosynthesis and Characterization}

$\mathrm{ZnO}$ micro/nanoferns were potentiostatically electrodeposited at $-1.0 \mathrm{~V}$ (vs. $\mathrm{Ag} / \mathrm{AgCl} / \mathrm{KCl}(3 \mathrm{M})$ ) using a $0.5 \mathrm{mM} \mathrm{ZnCl}_{2}$ (Fluka, $\left.>98.0 \%\right)+0.1 \mathrm{M} \mathrm{KCl}$ (Sigma, $>99.0 \%$,) oxygen-saturated aqueous solution ( $\mathrm{pH}=7$ in standard conditions) that was bubbled for $45 \mathrm{~min}$ before and during electrodeposition, and ultimately maintained at $80^{\circ} \mathrm{C}$. A classical three-electrode electrochemical cell, an Autolab with a PGSTAT30 potentiostat-galvanostat, and NOVA software were used in the electrodeposition process. Working, counter, and reference electrodes were comprised of fluorine-doped tin oxide film on a glass substrate, a Pt mesh, and $\mathrm{Ag} / \mathrm{AgCl} / \mathrm{KCl}(3 \mathrm{M}$ ), respectively. Strong stirring (400 rpm of magnetic stirring and 1,3 , or $12 \mathrm{~L} \mathrm{~min}^{-1}$ of oxygen bubbling) during electrodeposition ensured the achievement of the micro/nanofern architecture. The deposited $\mathrm{ZnO}$ micro/nanoferns were then sulfidated to obtain ZnO@ZnS core@shell micro/nanoferns by immersion in an aqueous solution of $30 \mathrm{mM}$ thioacetamide (Sigma-Aldrich, $98 \%$,) at $40{ }^{\circ} \mathrm{C}$ in a water bath for $4 \mathrm{~h}$, followed by annealing for $2 \mathrm{~h}$ at $400{ }^{\circ} \mathrm{C}$ in an argon atmosphere as described in References [1,44].

The surface morphologies and elemental compositions of the micro/nanoferns were examined by field-emission scanning electron microscopy (FE-SEM, Hitachi S-4800 and H-4100FE, Ibaraki, Japan) with an energy-dispersive $\mathrm{X}$-ray spectroscopy detector. The specific surface area of each photocatalyst was determined using the Brunauer-Emmett-Teller (BET) method based on $\mathrm{N}_{2}$ adsorption-desorption isotherms obtained at $77 \mathrm{~K}$ using a Micrometrics Tristar-II (Micrometrics, Canada). The optoelectronic properties of micro/nanoferns were determined from UV-vis diffuse reflectance spectra (DRS) recorded using a Lambda 900 UV spectrophotometer (PerkinElmer, Massachusetts, United States).

\subsection{Adsorption Experiments}

Adsorption experiments for $\mathrm{MB}$ and $\mathrm{Cr}(\mathrm{VI})$ ions were conducted in dark conditions at a fixed temperature $\left(25 \pm 0.2^{\circ} \mathrm{C}\right)$ and $\mathrm{pH}(9.5)$ using the prepared $\mathrm{ZnO}$-based micro/nanoferns (adsorbent dosage $=0.4 \mathrm{mg} \mathrm{mL}^{-1}$ ) and single-pollutant solutions, either $5 \mathrm{ppm}$ of $\mathrm{MB}$ (Sigma-Aldrich, $>97 \%$ ) or $20 \mathrm{ppm}$ of $\mathrm{Na}_{2} \mathrm{CrO}_{4}$ (Sigma-Aldrich, $>98 \%$ ). During the adsorption process, the solutions were magnetically stirred continuously $(150 \mathrm{rpm})$ to improve mass transport. Adsorption kinetics were determined by analyzing the adsorptive uptake of $\mathrm{MB}$ and $\mathrm{Cr}(\mathrm{VI})$ ions at different time intervals (total adsorption time $=120 \mathrm{~min}$ ) using a UV-visible spectrophotometer; specifically, absorbance changes were monitored at the respective $\lambda_{\max }$ values of $662 \mathrm{~nm}$ and $372 \mathrm{~nm}$ for $\mathrm{MB}$ and $\mathrm{Cr}(\mathrm{VI})$. In all experiments, the pollutant solutions were prepared in a saline medium (medium A; $0.5 \mathrm{~g} \mathrm{~L}^{-1}$ of $\mathrm{NaHCO}_{3}+0.5 \mathrm{~g} \mathrm{~L}^{-1}$ of $\mathrm{K}_{2} \mathrm{HPO}_{4}+1.5 \mathrm{~g} \mathrm{~L}^{-1}$ of $\mathrm{NaNO}_{3}+1.0 \mathrm{~g} \mathrm{~L}^{-1}$ of $\mathrm{K}_{2} \mathrm{SO}_{4}+1.0 \mathrm{~g} \mathrm{~L}^{-1}$ of NaCl+0.04 $\mathrm{g} \mathrm{L}^{-1} \mathrm{CaCl}_{2}$ ) [20].

\subsection{Photocatalysis experiments}

Photooxidation and photoreduction experiments were performed under a 75-W Xe lamp set-up with UV-filtered simulated sunlight (light intensity $=680 \pm 10 \mathrm{~lx}$ ) or UV-filtered natural sunlight (light intensity $=540 \pm 15$ lx). Following the International Organization for Standardization (10678:2010 standard), longpass filters (cut-on wavelength region: 400-2200 nm) were introduced to limit wavelength radiation and to prevent direct photolysis of the pollutants. Before photocatalysis, the photocatalysts were immersed in each pollutant solution for $60 \mathrm{~min}$ in the dark to attain adsorption-desorption equilibrium. During photocatalysis, the pollutant solutions were maintained under controlled conditions (temperature $=25 \pm 0.2{ }^{\circ} \mathrm{C}$; photocatalyst dosage $=0.4 \mathrm{mg} \mathrm{mL}^{-1}$ ). In all experiments, pollutant solutions were prepared with the saline medium A. 
The photooxidation activity of $\mathrm{ZnO}$-based micro/nanoferns was evaluated by monitoring the decomposition of a single-pollutant solution containing $5 \mathrm{ppm}$ of $\mathrm{MB}, 4-\mathrm{NP}$, or Rh-B and a complex solution of three POPs (5 ppm of $\mathrm{MB}+5 \mathrm{ppm}$ of $4-\mathrm{NP}+5 \mathrm{ppm}$ of Rh-B pollutants). Similarly, photoreduction activity was evaluated by monitoring the reduction of $\mathrm{Cr}$ (VI) to $\mathrm{Cr}$ (III) in a single-pollutant solution containing $20 \mathrm{ppm}$ of $\mathrm{Na}_{2} \mathrm{CrO}_{4}$. The possible synergetic effects of organic-inorganic pollutants on the photooxidation and photoreduction processes were investigated by tracking the photodegradation of $\mathrm{MB}$ and the photoreduction of $\mathrm{Cr}(\mathrm{VI})$ in a bi-pollutant solution ( $5 \mathrm{ppm}$ of $\mathrm{MB}+20 \mathrm{ppm}$ of $\mathrm{Na}_{2} \mathrm{CrO}_{4}$ ). All reactions were carried out under UV-filtered simulated sunlight and UV-filtered natural sunlight.

In the photoreduction of $\mathrm{MB}$ and $\mathrm{Cr}(\mathrm{VI})$, degradation efficiency was tracked using UV-vis spectroscopy (UV-1800 spectrophotometer, Shimadzu) in a quartz cuvette with an optical length of $1 \mathrm{~cm}$. Specifically, for MB, 4-NP, and Rh-B, the degradation efficiencies were determined from the temporal evolution of the reduction in peak intensity at $\lambda_{\mathrm{m}}=662,400$, and $554 \mathrm{~nm}$, respectively, during a 60-min period of irradiation. For $\mathrm{Cr}(\mathrm{VI})$, degradation efficiency was determined by monitoring the peak intensity at $\lambda_{\mathrm{m}}=372 \mathrm{~nm}$ over $180 \mathrm{~min}$ of irradiation. In addition, photomineralization was determined for all solutions by comparison of the total organic content (TOC) before the start of irradiation to that after irradiation. Organic content was determined by high-temperature combustion on a catalyst $\left(\mathrm{Pt}-\mathrm{Al}_{2} \mathrm{O}_{3}\right)$ in a tubular flow microreactor operated at $680^{\circ} \mathrm{C}$, with a stream of hydrocarbon-free air to oxidize the organic carbon (TOC-VCSN instrument with a high-sensibility column, Shimadzu).

The photostability and reusability of ZnO-based micro/nanoferns for the photooxidation of $\mathrm{MB}$ at different $\mathrm{pH}(5.5,7.5$, and 9.5) and the photoreduction of $\mathrm{Cr}(\mathrm{VI})$ were evaluated over six cycles of reuse under UV-filtered simulated sunlight.

\section{Conclusions}

$\mathrm{ZnO}$ micro/nanofern micro/nanostructures were easily synthesized via a facile electrodeposition process in strong stirring conditions (400 rpm of magnetic stirring and 1,3, or $12 \mathrm{~L} \mathrm{~min}^{-1}$ of oxygen bubbling). The effects of oxygen flux on the micro/nanofern architecture (i.e., multiple and fractal ramifications) were explored, illustrating the importance of oxygen bubbling on the formation of multiple ramifications and, consequently, the electrosynthesis of well-defined micro/nanoferns. The micro/nanofern architecture offered excellent photocatalytic performance due to its higher capability to trap light and to adsorb pollutants. However, sulfidation, which leads to the formation of ZnO@ZnS core@shell micro/nanoferns, is required to simultaneously improve both the photoresponse to the visible region and photocorrosion resistance (i.e., photocatalyst lifetime). Additionally, the $\mathrm{ZnS}$ surface also exhibited improved adsorption affinity. These ZnO@ZnS core@shell micro/nanoferns were excellent photocatalysts under irradiation by UV-filtered sunlight, able to photodegrade nearly $97 \%$ of $\mathrm{MB}$ after $60 \mathrm{~min}$; mineralize $>98 \%$ of a mixture of $\mathrm{MB}, 4-\mathrm{NP}$, and Rh-B after $210 \mathrm{~min}$; and remove nearly $65 \%$ of $\mathrm{Cr}(\mathrm{VI})$ after $180 \mathrm{~min}$. In addition, they demonstrated improved photodegradation efficiency in a more realistic environment containing both $\mathrm{MB}$ and $\mathrm{Cr}(\mathrm{VI})$, in which $\mathrm{Cr}(\mathrm{VI})$ contributed to capturing electrons and consequently inhibited the recombination process. Finally, superior recyclability and reusability properties were observed for the sulfidated microstructures, especially at low sulfidation times (i.e., thinner ZnS layers). The excellent photocatalytic performance in both photooxidation of POPs and photoreduction of $\mathrm{Cr}(\mathrm{VI})$ demonstrates the viability of bioinspired $\mathrm{ZnO} @ \mathrm{ZnS}$ micro/nanoferns.

Supplementary Materials: The following are available online at http://www.mdpi.com/2073-4344/9/12/974/s1, Figure S1: X-ray diffraction patterns of ZnO-based photocatalysts, Figure S2: Field emission electron microscopy micrographs of ZnO-based micro/nanoferns, Figure S3: Photocatalytic degradation of MB, Figure S4: Photolysis of MB, 4-NP, and Rh-B, figure S5: Photoreduction of $\mathrm{Cr}(\mathrm{VI})$, Figure S6: Photoreduction of $\mathrm{Cr}(\mathrm{VI})$.

Author Contributions: Conceptualization, A.S., E.G. and L.P.; methodology, A.S.; validation, A.S., E.G. and L.P.; formal analysis, A.S., E.G. and L.P.; investigation, A.S.; resources, E.G. and L.P.; data curation, A.S.; writing-original draft preparation, A.S.; writing-review and editing, A.S., E.G. and L.P.; visualization, A.S.; supervision, E.G. and L.P.; project administration, L.P.; funding acquisition, E.G. and L.P. 
Funding: This work was partially supported by the Metrohm foundation. Partial funding from the TEC2017-85059-C3-2-R project (co-financed by the Fondo Europeo de Desarrollo Regional, FEDER) from the Spanish Ministerio de Economía y Competitividad (MINECO) is also acknowledged. Albert Serrà would like to acknowledge funding from the EMPAPOSTDOCS-II program. The EMPAPOSTDOCS-II program has received funding from the European Union's Horizon 2020 research and innovation program under the Marie Skłodowska-Curie grant agreement number 754364.

Conflicts of Interest: The authors declare no conflict of interest.

\section{References}

1. Serrà, A.; Zhang, Y.; Sepúlveda, B.; Gómez, E.; Nogués, J.; Michler, J.; Philippe, L. Highly active ZnO-based biomimetic fern-like microleaves for photocatalytic water decontamination using sunlight. Appl. Catal. B Environ. 2019, 248, 129-146. [CrossRef]

2. Hoffmann, M.R.; Martin, S.T.; Choi, W.; Bahnemann, D.W. Environmental applications of semiconductor photocatalysis. Chem. Rev. 1995, 95, 69-96. [CrossRef]

3. Linsebigler, A.L.; Lu, G.; Yates, J.T. Photocatalysis on $\mathrm{TiO}_{2}$ surfaces: Principles, mechanisms, and selected results. Chem. Rev. 1995, 95, 735-758. [CrossRef]

4. Saravanan, R.; Karthikeyan, S.; Gupta, V.K.; Sekaran, G.; Narayanan, V.; Stephen, A. Enhanced photocatalytic activity of $\mathrm{ZnO} / \mathrm{CuO}$ nanocomposite for the degradation of textile dye on visible light illumination. Mater. Sci. Eng. C 2013, 33, 91-98. [CrossRef] [PubMed]

5. Sun, J.; Yuan, Y.; Qiu, L.; Jiang, X.; Xie, A.; Shen, Y.; Zhu, J. Fabrication of composite photocatalyst g- $\mathrm{C}_{3} \mathrm{~N}_{4}-$ $\mathrm{ZnO}$ and enhancement of photocatalytic activity under visible light. Dalton Trans. 2012, 41, 6756. [CrossRef] [PubMed]

6. Luo, Q.; Yu, X.; Lei, B.; Chen, H.; Kuang, D.; Su, C. Reduced graphene oxide-hierarchical ZnO hollow sphere composites with enhanced photocurrent and photocatalytic activity. J. Phys. Chem. C 2012, 116, 8111-8117. [CrossRef]

7. Boon, C.; Yong, L.; Wahab, A. A review of $\mathrm{ZnO}$ nanoparticles as solar photocatalysts: Synthesis, mechanisms and applications. Renew. Sustain. Energy Rev. 2018, 81, 536-551.

8. Byrne, C.; Subramanian, G.; Pillai, S.C. Recent advances in photocatalysis for environmental applications. J. Environ. Chem. Eng. 2018, 6, 3531-3555. [CrossRef]

9. Qi, J.; Zhang, W.; Cao, R. Solar-to-hydrogen energy conversion based on water splitting. Adv. Energy Mater. 2018, 8, 1-16. [CrossRef]

10. Wang, H.; Lin, Q.; Yin, L.; Yang, Y.; Qiu, Y.; Lu, C.; Yang, H. Biomimetic design of hollow flower-like g- $\mathrm{C}_{3} \mathrm{~N}_{4} @ \mathrm{PDA}$ organic framework nanospheres for realizing an efficient photoreactivity. Small 2019, 15, 1-8. [CrossRef]

11. Zhang, G.; Chen, D.; Li, N.; Xu, Q.; Li, H.; He, J.; Lu, J. Fabrication of $\mathrm{Bi}_{2} \mathrm{MoO}_{6} / \mathrm{ZnO}$ hierarchical heterostructures with enhanced visible-light photocatalytic activity. Appl. Catal. B Environ. 2019, 250, 313-324. [CrossRef]

12. Sapkota, K.P.; Lee, I.; Hanif, A.; Islam, A. Carbon nanotube photocatalyst for the degradation of a persistent water pollutant organic dye. Catalysts 2019, 9, 498. [CrossRef]

13. Violet, C.; Franco, P.; Sacco, O.; Marco, I. Zinc oxide nanoparticles obtained by supercritical antisolvent precipitation for the photocatalytic degradation of crystal violet dye. Catalysts 2019, 9, 346 .

14. Fei, W.; Song, Y.; Li, N.; Chen, D.; Xu, Q.; Li, H.; He, J.; Lu, J. Fabrication of visible-light-active ZnO/ZnFe-LDH heterojunction on $\mathrm{Ni}$ foam for pollutants removal with enhanced photoelectrocatalytic performance. Sol. Energy 2019, 188, 593-602. [CrossRef]

15. Bao, C.; Chen, M.; Jin, X.; Hu, D.; Huang, Q. Efficient and stable photocatalytic reduction of aqueous hexavalent chromium ions by polyaniline surface-hybridized ZnO nanosheets. J. Mol. Liq. 2019, 279, 133-145. [CrossRef]

16. Yuan, X.; Cheng, X.; Jing, Q.; Niu, J.; Peng, D.; Feng, Z.; Wu, X. ZnO/ZnAl $\mathrm{O}_{4}$ nanocomposite with 3D sphere-like hierarchical structure for photocatalytic reduction of aqueous $\mathrm{Cr}(\mathrm{VI})$. Materials 2018, 11, 1624. [CrossRef]

17. Shraavan, S.; Challagulla, S.; Banerjee, S.; Roy, S. Unusual photoluminescence of $\mathrm{Cu}-\mathrm{ZnO}$ and its correlation with photocatalytic reduction of Cr (VI). Bull. Mater. Sci. 2017, 40, 1415-1420. [CrossRef] 
18. Skompska, M.; Zar, K. Electrodeposition of ZnO nanorod arrays on transparent conducting substrates-A Review. Electrochim. Acta 2014, 127, 467-488. [CrossRef]

19. Environ, E.; Gu, V. From nanowires to hierarchical structures of template-free electrodeposited $\mathrm{ZnO}$ for efficient dye-sensitized solar cells. Energy Environ. Sci. 2011, 2971-2979.

20. Serrà, A.; Zhang, Y.; Sepúlveda, B.; Gómez, E.; Nogués, J.; Michler, J.; Philippe, L. Highly reduced ecotoxicity of $\mathrm{ZnO}$-based micro/nanostructures on aquatic biota: Influence of architecture, chemical composition, fixation, and photocatalytic efficiency. Water Res. 2019, 169, 115210. [CrossRef]

21. Vaiano, V.; Matarangolo, M.; Murcia, J.J.; Rojas, H.; Navío, J.A.; Hidalgo, M.C. Enhanced photocatalytic removal of phenol from aqueous solutions using $\mathrm{ZnO}$ modified with Ag. Appl. Catal. B Environ. 2018, 225, 197-206. [CrossRef]

22. Yu, X.X.; Wu, Y.; Dong, B.; Dong, Z.F.; Yang, X. Enhanced solar light photocatalytic properties of ZnO nanocrystals by Mg-doping via polyacrylamide polymer method. J. Photochem. Photobiol. 2018, 356, 681-688. [CrossRef]

23. Sekar, A.D.; Muthukumar, H.; Chandrasekaran, N.I.; Matheswaran, M. Photocatalytic degradation of naphthalene using calcined Fe-ZnO/PVA nanofibers. Chemosphere 2018, 205, 610-617. [CrossRef] [PubMed]

24. Yuan, X.; Wu, X.; Feng, Z.; Jia, W.; Zheng, X.; Li, C. Facile synthesis of heterojunctioned $\mathrm{ZnO} / \mathrm{Bi}_{2} \mathrm{~S}_{3}$ nanocomposites for enhanced photocatalytic reduction of aqueous $\mathrm{Cr}(\mathrm{VI})$ under visible-light irradiation. Catalysts 2019, 9, 624. [CrossRef]

25. Liu, N.; Li, Z. Materials science in semiconductor processing bimetal-organic frameworks derived carbon doped $\mathrm{ZnO} / \mathrm{Co}_{3} \mathrm{O}_{4}$ heterojunction as visible-light stabilized photocatalysts. Mater. Sci. Semicond. Process. 2018, 79, 24-31. [CrossRef]

26. Fathi, M.; Esmail, A. Pollutant degradation of different organic dyes using the photocatalytic activity of ZnO@ZnS nanocomposite materials. J. Environ. Chem. Eng. 2018, 6, 3981-3990.

27. Yousefi, R.; Jamali-sheini, F.; Cheraghizade, M. Enhanced visible-light photocatalytic activity of strontium-doped zinc oxide nanoparticles. Mater. Sci. Semicond. Process. 2015, 32, 152-159. [CrossRef]

28. Qamar, M.T.; Aslam, M.; Ismail, I.M.I.; Salah, N.; Hameed, A. Synthesis, Characterization, and Sunlight Mediated Photocatalytic Activity of $\mathrm{CuO}$ Coated $\mathrm{ZnO}$ for the Removal of Nitrophenols. ACS Appl. Mater. Interfaces 2015, 7, 8757-8769. [CrossRef]

29. Servant, L. Nanoparticulate heterostructures due to inhomogeneous space charge effects. Phys. Chem. Chem. Phys. 2015, 17, 5090-5102.

30. Verma, S.; Dutta, R.K. Enhanced ROS generation by ZnO-ammonia modified graphene oxide nanocomposites for photocatalytic degradation of trypan blue dye and 4-nitrophenol. J. Environ. Chem. Eng. 2017, 5, 4776-4787. [CrossRef]

31. Jadhav, J.; Biswas, S. Hybrid ZnO: Ag core-shell nanoparticles for wastewater treatment: Growth mechanism and plasmonically enhanced photocatalytic activity. Appl. Surf. Sci. 2018, 456, 49-58. [CrossRef]

32. Jin, Y.; Long, J.; Ma, X.; Zhou, T.; Zhang, Z.; Lin, H.; Long, J.; Wang, X. Synthesis of caged iodine-modified $\mathrm{ZnO}$ nanomaterials and study on their visible light photocatalytic antibacterial properties. Appl. Catal. B Environ. 2019, 256, 117873. [CrossRef]

33. Gadisa, B.T.; Appiah-Ntiamoah, R.; Kim, H. In-situ derived hierarchical ZnO/Zn-C nano fiber with high photocatalytic activity and recyclability under solar light. Appl. Surf. Sci. 2019, 491, 350-359. [CrossRef]

34. Alkaim, A.F.; Aljeboree, A.M.; Alrazaq, N.A.; Baqir, S.J.; Hussein, F.H.; Lilo, A.J. Effect of pH on adsorption and photocatalytic degradation efficiency of different catalysts on removal of methylene blue. Asian J. Chem. 2014, 26, 6097-6100. [CrossRef]

35. Kong, J.Z.; Li, A.D.; Li, X.Y.; Zhai, H.F.; Zhang, W.Q.; Gong, Y.P.; Li, H.; Wu, D. Photo-degradation of methylene blue using Ta-doped ZnO nanoparticle. J. Solid State Chem. 2010, 183, 1359-1364. [CrossRef]

36. Talebian, N.; Nilforoushan, M.R. Comparative study of the structural, optical and photocatalytic properties of semiconductor metal oxides toward degradation of methylene blue. Thin Solid Films 2010, 518, 2210-2215. [CrossRef]

37. Chakraborty, T.; Chakraborty, A.; Shukla, M. ZnO-Bentonite nanocomposite: An efficient catalyst for discharge of dyes, phenol and $\mathrm{Cr}(\mathrm{VI})$ from water. J. Coord. Chem. 2019, 72, 53-68. [CrossRef]

38. Yuan, X.; Feng, Z.; Zhao, J.; Niu, J.; Liu, J.; Peng, D.; Cheng, X. Significantly enhanced aqueous Cr(VI) removal performance of $\mathrm{Bi} / \mathrm{ZnO}$ nanocomposites via synergistic effect of adsorption and SPR-promoted visible light photoreduction. Catalysts 2019, 8, 426. [CrossRef] 
39. Kabra, K.; Chaudhary, R.; Sawhney, R.L. Treatment of hazardous organic and inorganic compounds through aqueous-phase photocatalysis: A Review. Ind. Eng. Chem. Res. 2004, 43, 7683-7696. [CrossRef]

40. Sasikala, S.P.; Nibila, T.A.; Babitha, K.B.; Mohamed, A.A.P.; Solaiappan, A. Competitive photo-degradation performance of $\mathrm{ZnO}$ modified bentonite clay in water containing both organic and inorganic contaminants. Sustain. Environ. Res. 2019, 29, 1-12. [CrossRef]

41. Egerton, T.A.; Mattinson, J.A. Comparison of photooxidation and photoreduction reactions on $\mathrm{TiO}_{2}$ nanoparticles. J. Photochem. Photobiol. A Chem. 2007, 186, 115-120. [CrossRef]

42. Mara, D. The all-inclusive sustainable development goals: The WASH professional's guide (or should that be 'nightmare'?). J. Water Sanit. Hyg. Dev. 2016, 6, 349-352. [CrossRef]

43. Assembly, T.G.; Rights, C.; Rights, P. Presented at General Assembly, Denver, CO, USA, September 2016.

44. Shanmugam, K.; Burgos, R.; Sillanpaa, M. Effective shell wall thickness of vertically aligned $\mathrm{ZnO}-\mathrm{ZnS}$ core-shell nanorod arrays on visible photocatalytic and photo sensing properties. Appl. Catal. B Environ. 2018, 237, 128-139.

(C) 2019 by the authors. Licensee MDPI, Basel, Switzerland. This article is an open access article distributed under the terms and conditions of the Creative Commons Attribution (CC BY) license (http://creativecommons.org/licenses/by/4.0/). 